\title{
On approaching schizophrenia through Wittgenstein
}

\author{
RUPERT READ
}

ABSTRACT Louis Sass disputes that schizophrenia can be understood successfully according to the hitherto dominant models - for much of what schizophrenics say and do is neither regressive (as psychoanalysis claims) nor just faulty reasoning (as “cognitivists" claim). Sass argues instead that schizophrenics frequently exhibit hyper-rationality, much as philosophers do. He holds that schizophrenic language can after all be interpreted-if we hear it as Wittgenstein hears solipsistic language. I counter first that broadly Winchian considerations undermine both the hermeneutic conception of interpreting other humans in general and Sass's hope of interpreting schizophrenics in particular. I then go on to argue that even if these Winchian considerations are not accepted, Sass in any case doesn't take sufficiently seriously Wittgenstein's use of nonsense as a term of criticism. Solipsism is not something we can understand so as to be able to understand analogically the schizophrenic's "world"-for there is no such thing as understanding it. Solipsism is nonsense, is nothing - there is no "world" there, in solipsists (as I show by reference to Cora Diamond's reading of Wittgenstein). Nor in any actually analogous cases of schizophrenia. Their "alienness" is the alienness of nothingness; roughly, of the fantasy of "logically alien thought".

Suppose you say of the schizophrenic: he does not love, he cannot love, he refuses to love-what is the difference?! (Wittgenstein, 1980)

This paper concerns the most elusive, perhaps the strangest, surely the most philosophically charged of "mental illnesses": schizophrenia. My central question might be put this way: what kind of light (if any) can Wittgenstein's philosophy shed on this near-unapproachable phenomenon?

"Schizophrenia" is a strange (and heterogenous) psychopathology. It has strenuously resisted efforts to interpret it. Karl Jaspers is only one of its more famous analysers to have despaired at times; he declared it "incomprehensible", "psychologically inaccessible" and "closed to empathy" [1]; somewhat unlike, say, depression, and most "neuroses".

The aim of this paper is to set out my arguments as to whether we can hope to interpret "schizophrenic language", and thereby to establish how, if at all, to "read" this especially difficult form of "mental illness", via a reading of Wittgenstein's philosophy.

Rupert Read, SOC, University of East Anglia, Norwich NR4 7TF, UK, email: R.Read@uea.ac.uk 
The means by which I hope to achieve these aims is as follows: I offer a critique of what is probably the most important philosophically informed effort in this generation to understand what schizophrenia is, and how the forms of its language can be comprehended. The effort is that of Louis Sass, who has endeavoured to overturn the conventional wisdom as to the nature of schizophrenia. Whereas schizophrenia is almost invariably seen as a disease of functional or cognitive deficit, or of affective excess and regression [2], Sass uses Wittgenstein to read it instead as centring on alienation, cognitive excess, hyper-reflexivity, even "hyper-rationality".

Terms like "alienation" might strike the reader as especially relevant to Modern European life. And indeed, the form- "the logic"-of Modernism in art and literature is held by Sass to be relevantly similar to that of schizophrenia. He holds the form of much philosophy (e.g. the Early Modern philosophy of the "way of ideas"; "Kantian" and most "post-Kantian" philosophy; and more recently "Deconstructionism" [3]) to be similarly analogous. Sass further holds that the counter-philosophy of Wittgenstein [4] appropriately describes and most effectively diagnoses these "logics", these forms.

My paper is structured as follows. I give a fairly detailed sketch of Sass's work (Section 1), expounding his original interpretation of schizophrenia and his "Wittgensteinian" arguments for that interpretation. Following that, in Section 2, I give my criticisms of Sass, drawing principally on writers I consider to be the foremost Wittgensteinians of recent times. My criticisms are given in the form of a a series of three closely connected questions, my answers to which constitute objections that I take to be fundamental both to Sass's project and (more generally) to any attempt to develop a hermeneutic for schizophrenia. My purpose is systematically to doubt whether schizophrenia can be interpreted at all; even along Sass's ("promising") lines. Finally (Section 3), I draw some pretty radical conclusions from my arguments of the previous section.

\section{Exposition of Sass}

In this section, I refrain from giving my own views, and concentrate on expounding the most detailed exemplification of Sass's general thesis: the case of Daniel Paul Schreber, the most famous psychiatric patient in history, in some respects a "prototypical" paranoid schizophrenic, considered in the light of Wittgenstein's thought. Sass's book is called The Paradoxes of Delusion: Wittgenstein, Schreber and the Schizophrenic Mind [5].

Two preliminary notes, before we get properly underway:

1. Sass is optimistic but not over-reachingly so about the range of phenomena with which his approach, as initially outlined above, will cope: namely, with some central difficult aspects of a good number of serious cases of schizophrenia, and especially, as we shall see, with certain classes of cases which hitherto have been very ill-understood. (Furthermore, I would add what I cannot explore further here: that Sass's approach arguably fits ill-understood aspects of some other mental disorders, especially high-functioning autism-Asperger's, etc.-some 
central portions of Obsessive-Compulsive Disorder, and perhaps Dissociative Identity Disorder, formerly MPD [6].)

2. It is important to note specifically that Sass does not prejudge against some of schizophrenia having a genetic "basis", still less against its being correlated with changes in the brain. In short, Sass, while not unimpressed by socio-cultural elements probably involved in the genesis as well as in the plasticity of schizophrenia [7], does not place these elements centrally in his studies. He is not a fanatic of "social constructivism", still less a Dualist.

To the central topic of this section: how does Sass read schizophrenia?

Schizophrenia is seen by Sass as involving not cognitive deficit, but cognitive "overwork" (and thus, sometimes, overload). People with schizophrenia suffer, roughly, from thinking too much; they think through things that most people do automatically. According to Sass, schizophrenia is-to coin Nietzsche's key opposition from "The Birth of Tragedy"-more essentially Apollonian than Dionysian ...

Schizophrenics live out philosophy: they "think things through" that normally get presupposed [8]. When philosophers do this, it's a limited academic exercise; when schizophrenics do it, it's all too serious. It's inchoate, too: but that is largely because the (philosophical) attempts to uncover the "underlying structure" of our experience are, arguably, themselves very largely inchoate. That is-according to Wittgenstein and company - the projects of Foundationalism, and "Kantianism", which would uncover such underlying structure, are in principle impossible. (We will return to this, in connection with Wittgenstein's Tractatus Logico-Philosophicus [9].)

The nature of schizophrenic language and experience is by this comparison arguably rendered surprisingly comprehensible. Sass's would-be Wittgensteinian "hermeneutical description" [10] of schizophrenia facilitates our understanding of why Schreber et al. think and act in the ways they do, and of how those ways have a certain logic, even a kind of scientificity, rather than being expressions of a mere primitivity or deficit.

What Schreber is-what he and other schizophrenics, including well-known people such as "Renée", Wolfli, Artaud and Nijinsky, have written and said-can be understood — can be successfully interpreted — via Wittgenstein's philosophy. (This claim of Sass's will be the primary focus of my criticism in Section 2.)

In particular, the peculiar structure of the commitments of one philosophically inclined toward solipsism - the supposed belief that one is the only person who exists-is brilliantly dissected by Wittgenstein, and it is this dissection which Sass applies analogically to the case of schizophrenia. Sass shows how the directions in which Schreber's delusional system develops are relevantly similar to those of a would-be serious solipsist (or sceptic), and that solipsism in turn is best understood by means of Wittgenstein's diagnosis of it as a disease of the intellect. Wittgenstein argues that there is no stable position or belief which is solipsism, but that "it" is in continual internal tension. He thinks that "the solipsist" is confused by language, and thus finds it "inadequate" to her purposes, and feels herself under pressure to change it-and changing the surface form of her mode of speech, according to Wittgenstein, is the most that the solipsist actually can do [11]. For example, she 
can insist (pointlessly) on reserving the word "toothache" for her own toothache, and describe others as puppets exhibiting behaviour outwardly similar to the behaviour that occurs when there is "real" (i.e. the solipsist's) toothache. Those familiar with Schreber's Memoir may recall here Schreber's frustration with the inadequacies of language to express what he wants to say. And they might recall particularly striking coinages of Schreber's own, such as the neologism, "fleetingimprovised-men" [12]. It is terms such as this which are a starting point for the construal of Schreber as solipsistic. For at times Schreber apparently thought that the people around him were not real, but were mere imagos, continually destroyed and fleetingly recreated as he turned his gaze [13].

What, then, is Sass's aim in his philosophy of psychopathology? To show the form of fly and fly-bottle here [14]; to show that both are saliently similar to those that philosophers have deliberately attempted (respectively) to be and, arguably, to inter themselves in.

Sass proceeds by means of showing that what schizophrenic delusions ARE has generally been misunderstood; in particular, they are not normally instances of "poor reality-testing". Schizophrenics can be quite "certain" of their delusions-but they also frequently have something like an ironic attitude towards these very same delusions. They do not generally appear to mean what they say in the literal "hallucinatory" sense in which they are often heard by their pathologizers.

Furthermore, if schizophrenics do confuse the real and the unreal, it tends to be in the opposite direction from that supposed by conventional psychiatric wisdoms. That is, schizophrenics do not mistake the unreal for real; they mistake the real for the unreal. If these flies are caught in fly-bottles, it is not so much that they take their fly-bottle to be all of reality, as that they take even the fly-bottle to be unreal too! They do not act as if their delusions were reality; they act as if everything were a delusion:

Here is how one schizoaffective patient describes the unreality feeling that plagued her during much of her psychosis:

It is like a constant sliding and shifting ... or like watching a movie based on a play and, having once seen the play, realizing that the movie is a description of it and one that brings back memories and yet isn't real ... Even a description of it is unreal and tormenting, for it is horrifying and yet seems mild and vague, although it is acute. It is felt in an unreal way in that it isn't constant torture and yet never seems to leave and everything seems to slip away into impressions ... For what is, is, and yet what seems to be is always changing and drifting away into thought and ideas, rather than actualities ... [15]

"Even a description of $i t$ is unreal and tormenting ..." Everything that this patient's mind touches turns not to gold but to unreality. We have here "an impossible situation" that seems to want to be described in this way: here there is no reality to check an illusion by, here we cannot mount the usually effective response against a sceptical argument from illusion, that there must be a reality by 
comparison with which the illusion is shown and known to be an illusion. Here is a lived experience of there only being illusion. Perhaps philosophical scepticism is possible, liveable, after all [16]: as severe mental illness [17].

This, then, is Sass's claim: that "poor reality-testing" is an utterly inadequate model for schizophreniform actions [18]. Sass shows how key aspects of schizophrenia can be "explained" by means of his Wittgensteinian analogies, and his hermeneutical-cum-phenomenological interpretation. In short, Sass brings out the aspects of Schreber's thinking which are clearly solipsistic, and the aspects of his thinking which, while not so obviously solipsistic, do in fact follow from the logic of solipsism, when rigorously (after Wittgenstein) examined.

Consider, for example, the fairly frequent tension in cases of schizophrenia between a sense of the self as all-powerful, all-knowing - and a sense of the self as nothing at all. The latter might seem quite obviously to contradict the idea of taking solipsism as a "model" for schizophrenia. Because the doctrine of solipsism seems self-evidently to be all on the side of conceiving of the self as all there is. So we would appear to have here an objection to Sass. Sass however turns this objection on its head, to work as a powerful argument in favour of his reading of the form of schizophrenic discourse. Let us see how.

We start by noting the "scientific"-even inductivist-character of much of Schreber's reasoning [19]. But this can sometimes seem to be contravened by his willingness to entertain contradictory thoughts (including his "double-book-keeping"; see Sass, 1994, p. 21), for surely internal consistency is a basic mark of rational or scientific thinking:

Schreber's claims seem ... to involve a contradiction ... between two attitudes: one in which he accepts the essential innerness and privacy of his own claims, the other in which he assumes that they have some kind of objectivity ... This duality is hardly unique to Schreber: many schizophrenic patients who seem generally aware of the innerness of their claims also consider their delusions to be revelations of a truth that they assume to be, in some sense, both objective and potentially public in nature. [20]

So the worry is: either solipsism is just the belief that oneself is all, in which case it is not a good analogy for many of the features of schizophrenia which Sass wishes to bring out (such as ubiquitous unreality feelings, and delusions of surveillance). Or solipsism is both the self as all and as nothing, in which case isn't schizophrenic thinking simply irrationally self-contradictory, after all?

What Sass shows is that "solipsism", appearances to the contrary notwithstanding, is not all on the side of "self as all". Rather, following Wittgenstein's incisive analysis, there is endemic to solipsism an instability, an oscillation between self as all and self as nothing. (The self-contradictions of schizophrenia may then turn out to be direct effects of the kind of logically minded thinking involved in the pursuit of solipsism.) The contradictions "the solipsist" gets into are not irrational or pre-rational, but are rationality itself-or at least, an important form of what has come down to us as philosophical rationality_-"taken to its logical/rational conclusions": they 
are "a playing out of the inherently self-refuting nature of solipsism itself" (Sass, 1994, p. 55). The kind of self-refutation which occurs when a solipsist wants to say "I have got something which you haven't". Sass quotes Wittgenstein:

"At any rate, only I have got THIS".-What are these words for? They serve no purpose.-Can one not add: "There is here no question of a "seeing"- and therefore none of a "having"-nor of a subject, nor therefore of "I" either? Might I not ask; In what sense have you got what you are talking about and saying that only you have got it? Do you possess it? ... If as a matter of logic you exclude other people's having something, it loses sense to say that you have it. (1958/1953, para. 398)

... The solipsist - to borrow one of Wittgenstein's many metaphors for the futility of such metaphysical claims - is like someone who tries to measure his own height not by using an independent reference system but by placing his own hand on top of his head.

Schreber makes precisely this error, and it is an important source of his paranoid-grandiose sense that ... "everything that happens is in reference to me" [Memoirs, p. 197]. Thus he feels he has discovered a surprising empirical fact, that experience happens only here, when in fact his experience could not on principle happen anywhere else ... Schreber writes ..."I can no longer doubt that the so-called "play with human beings" (the effect of miracles) is limited to myself and to whatever constitutes my immediate environment at the time" [Memoirs, p. 32]. His proof of this discovery is curiously circular ... [as] can be seen in the following passage ....

In any case miracles occur only on my person or in my immediate vicinity. I have again received striking proof of this in the last few days which I think is worth mentioning here.... [S] everal gambolling mosquitos were ... produced by miracle in front of my face while I sat in the garden of the inn of the neighbouring village of Ebenheit during an excursion; and again they appeared only in my immediate vicinity [Memoirs, p. 233]. (Sass, 1994, p. 57)

The delightful "parody" of scientific methodology here in Schreber's relation to his solipsistic experiences is quite as clear as it is (presumably) unconscious. More crucially, as Sass remarks, "Notice the equivocation inherent in Schreber's phrase "my immediate vicinity": although he may think that he is referring to the kind of place that could be objectively defined ("by the bench", for example, as opposed to "over by the wall of the garden"), in actuality "my immediate vicinity" means something more like "wherever I happen to look" (Sass, 1994, p. 57). The lack of an independent reference point is vital to the instability of the "position" of the solipsistic thinker. Precisely through an effort to be scientifical, logical, and rigorous, she then gets into severe philosophical confusion.

Now, with the same logic and scientific doggedness, albeit in a manner and 
within a frame that renders it unstable, the solipsistic thinker needs to pursue the question of the existence of themselves, too:

Wittgenstein [argues that] the usual and unrigorous form of solipsism ("the world is my world") reduces by its own intrinsic logic to what might be calleda "no-ownership solipsism of the present moment"-a position that can be expressed as "whenever anything is seen, it is this which is seen". The undeniable reality of the experience one has turns out not to affirm the existence of the self one is ...

One might still claim that the self-as-subject exists, but just not in the same way that the objects of experience exist ... But for the solipsist who engages in a scrutinizing hyperawareness, insisting on the unreality of all that goes beyond that which is phenomenally present in a direct and almost concrete fashion, such a position would be contradictory. One might as well admit the existence of other minds, for they too can be invoked as presuppositions of observable facts (like facial expressions ...). No, the rigorous, hyperscrutinizing solipsist must not assume the existence of the self but only of that which is directly observed: experiences. (Sass, 1994, p. 69)

Here is the very transition we did not expect, in modelling schizophrenia on solipsism. A sense of the self as all, and of others as nothing, leads by its own logic to a sense of one's own self as nothing.

This provides the essentials of an answer to a complaint which might be levelled at Sass: that his account can hardly be right because Schreber is such a "inconstant" solipsist, at best. The complaint can be rejected, if Sass's arguments as summarized above are accepted, because pure solipisism leads logically to its own overturning [21]. Such that Schreberian "inconstancy" is quite to be expected.

In sum: we can now perhaps account for how Schreber's text and thought came to have the peculiar form it does. Schreber, if Sass is right, lived out the kinds of pathological solipsistic, etc. thought processes that Wittgenstein described and diagnosed for us [22].

G. K. Chesterton once wrote, "The madman is not the man who has lost his reason. The madman is the man who has lost everything except his reason" [23]. Sass's heterodox reading of schizophrenia fleshes out this lovely aphorism. Sass overturns the conventional wisdom in psychology - that schizophrenia ought to be interpreted primarily as a disease of regression, or of cognitive deficit [24]. Rather, schizophrenia is comprehensible as involving excessive self-consciousness, and its strange consequences... consequences that one also frequently finds in rarefied philosophical systems.

\section{Criticism of Sass's interpretation of schizophrenia}

In this section, I raise a series of three questions for Sass. These questions engender two main lines of criticism.

First, in questions (i) and (ii), I use Winch to argue against "interpretive" 
("hermeneutic") — and in favour of purely "descriptive"-understanding (of other persons). Thus I suggest reasons for being suspicious of Sass's account, as over-intellectualist: as placing the interpreter as chiefly a thinker in relation to the interpreted person; and (correlatively) as presupposing that the interpreted person too is primarily a thinker. In the course of my argument, I raise special difficulties for the project of interpreting schizophrenic persons, difficulties based upon the apparent impossibility of (self-)description of such persons.

Then, in question (iii), I draw on Diamond to argue that-even if we were to provisionally accept Sass's "solipsistic interpretation" of schizophrenia-we should hold firmly in mind that Wittgenstein's own account of "solipsism" takes seriously that "solipsism" is through and through a temptation, not a philosophical position or a state of mind. In short, that, so far as we can say, "solipsism" is a tempting tissue of nonsense and nothing more - in which case it (and "lived analogues" of it) cannot possibly without violence be interpreted into something comprehensible.

To lead into the first line of criticism just sketched, I begin with a question which entails consideration of some general issues concerning the nature of the understanding of persons.

Question (i): Does Sass succeed in describing schizophrenia, rather than in interpreting (or "explaining") it?

What is it to understand human action? Need it involve interpretation/explanation, or is that an overly intellectualistic starting point? Can it instead simply involve the description (or unprejudiced "seeing") of actions and of understandingsin-practice?

Arguably, in order to do "human science" well, one needs to assemble a careful and unimperialistic/unimpositional description of, roughly speaking, the self-understandings-in-action of the person or people one is studying. (I cannot defend this claim in the present paper: I refer the reader to Colin Lyas's book Peter Winch for discussion and support [25].) The "non-interpretivism" which I am recommending here need not be Positivistic, for it does not imagine perception or description as isolated and purely fact-gathering phenomena. Rather, after Wittgenstein, Austin, Winch and Garfinkel, the approach that I am recommending maintains that there is what we typically call description [26] (which is not best assimilated to interpretation), but does not fantasize that such description prescinds from one's grasp, as of a participant-observer in a practice, of that practice as a lived activity.

If one not only avoids explaining but avoids interpreting, then one avoids a hermeneutic. One hopes, that is, to avoid adding anything to people's practices as they themselves understand them (both explicitly-if and when (self-)interpretation is actually called for, and - the usual case- "implicitly", in practice). One hopes not to change the terms of the norms and rules which they are following [27].

In this connection, and to illustrate my view, it is perhaps useful to say that Winch hopes in his great paper on "Understanding a primitive society"-his critique of the great anthropologist, Evans-Pritchard-to be pointing the way toward a description of Azande magical practices which will not impose upon them [28]. And imposition will, he thinks, result from (and amount to) interpreting them or (worse) 
"explaining" them. Instead, Winch invites us to look at the language-game the Azande are actually playing:

It might ... appear as though we had clear grounds for speaking of the superior rationality of European over Zande thought, in so far as the latter involves a contradiction [over criteria for "witch-hood"] which it makes no attempt to remove and does not even recognize: one, however, which is recognizable as such in the context of European ways of thinking. But does Zande thought on this matter really involve a contradiction? It appears from Evans-Pritchard's account that the Azande do not press their ways of thinking about witches to a point at which they would be involved in contradictions. Someone may now want to say that the irrationality of the Azande in relation to witchcraft shows itself in the fact that they do not press their thought about it "to its logical conclusion". To appraise this point we must consider... whether someone who does press this conclusion is being more rational than the Azande, who do not. Some light is thrown on this question by Wittgenstein's discussion of a game ... [29]

Winch goes on to suggest that the Azande are "playing a different game":

It is noteworthy ... that the Azande, when the possibility of this contradiction about the inheritance of witchcraft is pointed out to them, do not come to regard their old beliefs in witchcraft as obsolete. [According to EvansPritchard himself:] "They have no theoretical interest in the subject". This suggests strongly that the context from which the suggestion about the contradiction is made, the context of our scientific culture, is not on the same level as the context in which the beliefs about witchcraft operate. Zande notions of witchcraft do not constitute a theoretical system in terms of which Azande try to gain a quasi-scientific understanding of the world. This in turn suggests that it is the European, obsessed with pressing Zande thought where it would not go-to a contradiction-who is guilty of misunderstanding, not the Zande. [30]

I claim that we have here an example of someone-Winch-being able quite successfully to "follow along with" an "alien" discourse without imposing on it or interpreting it in terms other than its own. (Winch claims, as quoted here, that it is precisely the pressing on to the "logical conclusion" characteristic of European theorists, rather like that of Schreber, as laid out in Section 1, which leads to the misunderstanding of the "logic-in-action" of an apparently "alien" discourse [31].)

One can then present (rather than re-present) the thought and language of an "alien". If it "hangs together", as Winch suggested Azande thought does; if it can be made sense of without being imposed upon; if its character is such that one can come to describe it accurately, in important part through understanding it as practitioners themselves understand it: then one can present it (without falsifying it) [32].

Let us take an example from Sass, of where we may adjudge his practice to be 
worrisome, to be un-Winchian and un-Wittgensteinian even as he is attempting to follow Wittgenstein:

Schreber's dream is that spirits should be drawn down toward him and perish therein. For example, he sometimes hears the spirit of his wife saying (more precisely, he hears it "represented as saying") "Let me"-words which he knew to mean let me "dissolve in my husband's body". Since the spirits of Schreber's cosmos represent potentially rivalrous conscious centres, their perishing in him can be interpreted as a conceding of defeat in the competition of consciousness. (Sass, 1994, p. 120, italics mine)

Well, indeed, it can be interpreted that way. Other somewhat plausible interpretations are available: e.g. a more or less Freudian interpretation, to the effect that the alleged wish of the spirit of Schreber's wife to dissolve in him is actually an expression of his own wishes to possess and express her "voluptuousness". But ... why ought we to be so quickly interpreting here at all? Oughtn't we to start with Schreber's experience in his/its own terms? Within those terms, nothing "represents" anything unless Schreber takes it to do so (As he does take certain words - a little bizarrely! - to symbolize certain sentences, as indeed in the quoted passage.) In Schreber's experience, spirits are drawn down toward him. No matter that we probably cannot take this remotely seriously. We have nevertheless to (try to) see what, if anything, we can understand it as meaning.

One might argue then that Sass's turn of phrase here betrays that he is palpably offering an interpretation of Schreber's experience, rather than trying as hard as he might to "let that experience speak for itself". And one might again take for purposes of comparison the situation of an anthropologist trying to let (the experiences of) a very different people speak for themselves. Thus compare (and contrast) Wittgenstein's attitude in his "Remarks on Frazer's Golden Bough". Or similarly, Winch's approach vis-á-vis the Azande's quasi-“double-book-keeping”. Apparently deeply bizarre and/or allegedly "contradictory" beliefs can proceed perfectly happily in tandem with a practical workaday attitude toward growing crops, etc.

One salient contrast to Sass is: Wittgenstein and Winch continually stress that the use of language is a practice which is nearly always [33] integrated with non-linguistic actions (see e.g. PI, para. 23, and PI, para. 7). So, whereas Winch looks at what the Azande are doing with and alongside their words, Sass tends to decontextualize Schreber's words, his "language" [34]. Though this is a cause for concern, it may in the end not do a great deal of harm, for two reasons. First, some at least of Schreber's thinking and speaking surely is as "intellectualistic" and purely linguistic as Sass supposes. Second, I am not at all convinced that much of Schreber's language can be made sense of even if one works really hard to contextualize it and see what is perhaps being accomplished with it (see below for detail).

Another salient contrast to Sass is perhaps in the end weightier: Wittgenstein and Winch do not - as Sass, to judge from his rhetoric above, does-aim to say, for example, what the Azande are "really" doing when they use their poison-oracles, etc. Except, that is, in the (vital) sense that Winch aims at a description which would reasonably well satisfy the Azande. Winch holds that sound social study must aim to 
yield a version that could in principle satisfy the criterion of being accepted by those being "accounted for". A very important difference of nuance from the case of schizophrenics now suggests itself: there is a serious issue as to whether in serious cases of schizophrenia there can be any question of taking seriously any affirmation which a schizophrenic were to make of one's interpretation of their condition, thought or feelings. Because their schizophrenia (launching them as it arguably does on a hyperreflexive "journey" which issues in nothing consistent) deprives them of being able to be taken seriously in any such affirmation (or denial); unlike, surely, the Azande. This raises a serious general question about what the criteria of correctness of interpretation could possibly be, in the case of anyone attempting to hermeneuticize schizophrenia; and ought to make us worry therefore about whether an "interpretation" could possibly be what we ought to look for, here.

And the comparison Sass relies on, with solipsism, does not appear to get him out of trouble. For what Sass analogizes to schizophrenia is crucially different from what Winch analogizes (and disanalogizes) to the Azande. "Solipsism", unlike (say) Christian prayer, or science, is (according to Wittgenstein's arguments [35], which Sass and I both mean to hold by) sheer nonsense, a restless and relentless failure to mean. So I'm not only in the business of denying that Sass's interpretive procedure can possibly work (though I am plainly suspicious of it as well as intrigued by it, and I am especially suspicious of his mode of presentation of it, as a successful interpretation, rather than simply as a comparison (see PI, para. 130), a comparison which may lessen our misunderstanding of something strange). I am suggesting that even if the Sassian analogy "works", even if schizophrenia can be said to be analogous to solipsism, still the analogy is surely no good to us in a central respect. For it has no positive analogical content. (Nonsense has no content. So the idea that we understand solipsism as a doctrine, with a distinctive and determinable phenomenology, is an illusion.) The breach between us and "solipsistic schizophrenics", unlike most breaches dividing us from people we find odd, such as perhaps Christians, or football fans, or "primitive" peoples, is then, it must seem, irreparable.

At the heart of Winch's conception, as we have seen, is the idea of looking at the "game" which a group of persons is playing, and looking for both what is helpful and what is wrong with possible analogies to it. Not looking for the analogy which purportedly "gets it dead right"-which "successfully interprets" it. Insofar as someone claims, "Here's how to understand $x$ fully!", where $x$ is a society (or a practice, or a person), one ought to be very wary. (Especially if involved in the claim is something which can arguably not be rendered effectively as anything other than nonsense!) Where Winch or a Winchian "human scientist" casts light on some object of social study, he does it to help repair a particular breach. That's all. He has no "grander" quasi-scientific ("social scientific"), epistemic or metaphysical task.

Let us focus in again, then, on the special difficulty facing the would-be interpreter of (e.g.) schizophrenia. Now, if one is "hovering", or flip-flopping, between alternative ways of expressing oneself (alternative ways of being understood), there will normally be available some resolution to such "hovering". Typically, one will settle on some form(s) of words. There is a qualitative difference between "hovering" when at least in principle a resolution of the hovering is available 
in one of these forms - and when it isn't. In the latter kind of case-as, arguably, in much severe schizophrenia-we lack I think a basis for rendering the utterances-the humans - in question genuinely intelligible.

Arguably, much more than "consistency" and order in logic, belief and visible action are required in order for a person to be intelligible. The full panoply of human expression and action, including perception, desire and affect, is needed. Where one of these is, we want to say, wholly lacking, as in some autism and schizophrenia, I think we just don't know in the end what to say about the experience of the persons concerned. I have noted that in the first instance we understand "only" the "everyday" things that others do. Unusual, "extraordinary" things-say, some of what happened in the Holocaust, or in Milgram's experiments, and certainly much religion, and much of what is done and thought in "primitive" societies - can, if we try and are fortunate, be understood (typically, through literature or through instances of social or socio-historical study). There is, I suggest, no task for a general social science here, merely particular tasks of repairing breaches in our ability to "grasp" or meet others. The utterly bizarre, the irreparably Other, the residuum which unfortunately cannot be understood at all, there are arbitrarily many ways of describing (or "interpreting") — and thus, unmisleadingly expressed, none. In factas I explain in greater detail below-when we really understand this, we may well find it most useful, least misleading, least confusing, to say: there's nothing there to understand. We are faced with sheer nonsense [36].

Perhaps the locus of the difference between Sass and Winch can then be re-expressed in this way: that the Azande way of life-strange to us as it is, and its strangeness needs emphasizing as Winch emphasizes it-nevertheless can in principle be understood. While the severe schizophrenic cannot. Because while the form of the former can be comprehended (provided one takes on board Wittgensteinian lessons about the role or otherwise of "logical contradiction" in the "game" that the Azande collectively play), the form of the latter goes beyond what can strictly be comprehended, and goes into what can only (again, after Wittgenstein) at best be "diagnosed". While there is, perhaps, something one can call a Zande "belief system" in action, albeit by our lights a pretty peculiar "system", there is often in schizophrenics only the illusion of a system - almost invariably with no community to sustain it [37]. Such an illusory "system" is such that within "it" one can find no real resting-place (Witness the endlessly unstable scientistical and solipsistical "dialectic" within Schreber's thought). And again, while the Zande do not press their thinking to what others try to impose on them as its "logical conclusion", Schreber et al. do so press their thinking (whether voluntarily or non-voluntarily, it is hard to say-even perhaps in principle impossible, and this too is important). Thus it is that Schreber continually finds himself in a continually puzzling circular paradoxicality. In an absence of self-understanding, in spite (indeed, arguably in part because) of all his efforts at reflection.

Consider the contrast between Winch on the "contradictions" found in Zande practices, etc. and Sass on the contradictions found in Schreber's writings etc. Winch is able to suggest a way in which misunderstanding of the Azande can be avoided-a way in which the "contradictoriness" of their beliefs can be seen 
primarily as an artefact of an unsympathetic stance toward the "primitive", an artefact of the importation of an inappropriate hermeneutic into Zandeland. Sass, like Winch, is interested in getting us to reassess the allegedly "primitive" thought style of a class of persons (And this is no coincidence; for the mentally ill have often been explicitly likened to "primitive" people, and such a likening is an explicit part of Sass's target, as outlined at the opening of my paper). Sass, like Winch, wants to help us understand the apparently contradictory nature of the thought of this class of persons. But in Sass's case, the contradictions remain firmly in place. We do not get from Sass a suggestion as to how the contradictoriness of schizophrenics" beliefs etc. can be explained away-actually, what we get is only a representation of that contradictoriness. A re-presentation, that is, of the nonsense, the failure to mean, of the thinking of Schreber et al.

I am not here making a criticism of Sass, except insofar as he does not sufficiently recognize the possibility that the kind of moves that Winch successfully makes just cannot be made with Schreber et al. That the contradictions of schizophrenia are so deep-set that there is no getting away from them. Sass does not dwell enough on how very little has been achieved, by way of laying the groundwork for an "interpretation" of someone, if we are able to say of them, "Look, I can get you to see how their mind works: it works in just the way a mind works when it is so completely overworked that it is just as if it isn't working at all ..."

All this would have the implication that, in the cases which most interest and puzzle us, there cannot be a successful interpretation of schizophrenia, primarily for this reason: that there simply aren't, here, any true self-understandings available. That such sufferers from schizophrenia do not exhibit the kind of understanding-inpractice of their own talk which in everyday human contexts we can-and normally must-take for granted. We might even say that there cannot, logically, be true self-understandings in severe schizophrenics (to facilitate criteria for others accurately understanding them) [38]. And without the existence of those, there can be no production of comprehension-yielding descriptions which could be the basis for interpretation(s) [39].

My answer to question (i) with which I have opened this section is then this: Sass, regrettably, does not describe schizophrenic persons, and that he interprets them is particularly worrying in light of the specific considerations (concerning the lack of criteria to govern interpretation in the case of serious cases of schizophrenia) which I have adduced.

Question (ii): In Sass's effort to comprehend schizophrenia, is there then a real danger that he goes too far in the opposite direction to the orthodoxy (that schizophrenia, insofar as it is comprehensible at all, is only so as "primitivity" [40], or as mental deficit, etc.) which he is overturning-that he makes schizophrenia hang together/make rational sense more than it in fact does [41]?

I have maintained that we must take Schreber's beliefs at face value if we can. We must at least "present" his words, and try to respond to them "sympathetically" without interpreting them into something they are not; and then ask ourselves 
honestly whether we can understand them. We must try to do so-and then perhaps recognize that often we simply can't succeed, any more than Schreber can, and that we'd be wasting our time were we to just press on regardless. My worry is this: that "interpretation" of Schreber is a dubious halfway house between the claim to understand and the admittance of incomprehension. (It gives the illusion of understandingwhile changing the subject.)

Let us take another example, to illustrate. This is "Renée" again:

... I [complained] bitterly that things were tricking me and [of] how I suffered because of it. As a matter of fact, these "things" weren't doing anything special; they didn't speak, nor attack me... It was their very presence that made me complain ... When ... I looked at a chair or a jug, I thought not of their use or function ... but as having lost their names, their functions and meaning; they became things and began to take on life, to exist.

This existence accounted for my great fear. In the unreal scene ... suddenly "the thing" sprang up. The stone jar, decorated with blue flowers, was there facing me, defying me with its presence... To conquer my fear I looked away. My eyes met a chair, then a table; they were alive, too, asserting their presence. I attempted to escape their hold by calling out their names. I said, "chair ... it is a chair". But the words echoed hollowly, deprived of all meaning: it had left the object ... so much so that on the one hand it was a living mocking thing, on the other, a name, robbed of sense, an envelope emptied of content. Nor was I able to bring the two together, but stood there rooted before them, filled with fear and impotence. [42]

Up to this point, it is perhaps very tempting to offer an interpretation of the deeply strange things Renée is saying, to try to give sense to what is evidently scaring and confusing her. One might even see what she says next as hardening firming up such an interpretation: "When I protested, 'Things are tricking me; I am afraid', and people asked specifically, 'Do you see the jug and chair as alive?' I answered, 'Yes, they are alive" ".

But one should be very wary. For the kicker is that Renée goes on once again to undercut (this, and I think any) interpretation: "And they, the doctors, too, thought I saw these things as humans whom I heard speak. But it was not that. Their life consisted uniquely in the fact that they were there, in their existence itself" [43].

This stops one in one's tracks. The chance one seemingly had of coming to understand Renee's strange world (via the concept of "personification", etc.) finally disappears fairly precisely at this moment. She has specifically ruled it out. Any way that she has of expressing her experience is "inadequate", and so of course she is not understood. Her confusion is irredeemable, irrevocable.

For surely there just isn't anything it can be for the life of objects to consist uniquely in their existence. This inchoate notion is surely stranger than anything in (say) Zande practices. One can and must look for context to ground one's understanding of something strange- - but I defy anyone to find a context in Renée's text 
or life for this remark. By which I mean: a context which results in its being able to be made sense of. I don't see how there is anything left which we can hear her as succeeding in saying with those words ...

To reiterate: like Winch, like any good Wittgensteinian (or indeed any good "human scientist"), I am interested in understanding other human beings, in understanding what they say, in making sense of it insofar as it's possible to do so. Like Winch, and many others, I am convinced that it is quite often the case that insufficient effort is taken by philosophers and psychiatrists and psychologists and anthropologists to understand the strange [44]. But sometimes one ends up judging that it's not possible to do what Winch et al. would want us to; in which case one ends up instead perhaps noting the interesting patterns in a discourse but concluding that nevertheless there is an irrevocable incoherence in it [45].

An incoherence that, of course, cannot be understood-for there just is nothing to understand in incoherence, in nonsense.

My answer to question (ii) then is that Sass does indeed make schizophrenia "hang together" and "make sense" considerably more than is prudent and indeed tenable.

Question (iii): Doesn't a sound understanding of Wittgenstein's thinking in any case raise doubts as to whether it could possibly be right for schizophrenia to turn out to make sense, truly to $\mathrm{BE}$ interpretable, if it is indeed "best interpreted" as a lived analogue of solipsism?

For the sake of argument, I am willing at this point to suspend most of the argument made thus far in this section. I find the answers I have essayed to questions (i) and (ii) above effective, and indeed pretty devastating for Sass's project of interpreting human beings, and interpreting schizophrenic persons in particular; but let us be as generous as possible to Sass. Let us for the sake of argument continue to run with his interpretation of schizophrenia for a little longer, and not worry about the appropriateness or possibility of giving schizophrenia an interpretation in the first place.

And so, to begin responding directly to question (iii).

I have already suggested that a right understanding of Wittgenstein on solipsism has at its centre Wittgenstein's use of the term "nonsense" as a term of criticism. That is, one need not concede that solipsism, an illusory stopping point on the nonsensical merry-go-round of philosophical "positions", gets as far as being a system. One can rather persuade (oneself and) others that they are only subject to a temptation, to an inchoate and self-defeating desire for a system hereabouts.

To justify these suggestions and claims fully, and thus to expand successfully on my earlier suggestions about the necessary limitations of the usefulness to Sass of the analogy with solipsism, I need to bring in the reading of (the early) Wittgenstein due to James Conant and Cora Diamond. This might seem surprising, for isn't it only in the later Wittgenstein that we find Wittgenstein critiquing "systems" on the grounds that they are both pointless and nonsensical? Didn't the early Wittgenstein in fact himself build a philosophical system?

The answer is: no-to both questions. Or so, at least, Conant and Diamond 
have cogently argued. Let us extensively quoting one detailed instance in Diamond, to show how she thinks that we are deeply mistaken if we imagine that Wittgenstein's early work is a "system" (rather than the illusion of a system), or that it is supposed to "show" a number of philosophical things which "unfortunately" cannot be said:

When Wittgenstein says that we cannot say [e.g.] "There are objects" [46], he does not mean "There are, all right, only that there are has to get expressed another way". That the sentence means nothing at all and is not illegitimate for any other reason, we do not see. We are so convinced that we understand what we are trying to say that we see only the two possibilities: it is sayable, it is not sayable. But Wittgenstein's aim is to allow us to see that there is no "it". [47]

It's not that one cannot assign a meaning to (e.g.) "There are objects". Rather, one has strong grounds for thinking that no assignment of meaning will satisfy one.

[T] here is no coherent understanding to be reached of what you wanted to say. It dissolves: you are left with the sentence-structure "A is an object", standing there ... innocently meaning nothing at all, not any longer thought of as illegitimate because of a violation of the principles of what can be put into words and what goes beyond them. Really to grasp that what you were trying to say shows itself in language is to cease to think of it as an inexpressible content: that which you were trying to say.

Take Wittgenstein's remark that there is only logical necessity [TLP 6.37 \& 6.375] ... Logical necessity is that of tautologies ... But the remark that there is only logical necessity is itself ironically self-destructive. It has the form ... of "There is only this sort of thing", i.e. it uses the linguistic forms in which we say that there are only thises rather than thises and thats. ... But whatever the sentence aims to do for us, it is not to place the kind of necessity there is as this sort rather than that. It does not convey to us the philosophical but unsayable fact that there is only tautology not genuinely substantial necessity. In so far as we grasp what Wittgenstein aims at, we see that the sentence-form he uses comes apart from his ... aim ... We throw away the sentences about necessity; they really are, at the end, entirely empty. But we shall be aware at the end that when we go in for philosophical thinking, the characteristic form of such thought is precisely that the sentence-forms we use come apart from what we have taken to be our aims [48].

Diamond et al. seek to understand the "logic" of the Tractatus - while leading up to the conclusion that it has in a vital sense no logic whatsoever. TLP's "logic" is a "logic" of illusion, of what we are inclined to believe, of a set of psychologically attractive but ultimately empty pseudo-claims (One is in an unstable "position"-an oscillatory non-position - as one reads it; in something like the way that one is caught in an unstability if one is caught in the "dialectic" of "solipsism".) TLP lures one 
into thinking that one has finally found a satisfactory philosophical system-and then progressively undercuts that thought.

It is important to realize that if Diamond and Conant are right, then these points about the nonsensicality ultimately of our philosophical urgings are surprisingly general. As Wittgenstein once remarked:

Though it is nonsense to say "I feel his pain", this is different from inserting into an English sentence a meaningless word, say "abracadabra" ... and from saying a string of nonsense words. Every word in ["I feel his pain"] is English, and we shall be inclined to say that the sentence has a meaning. The sentence with the nonsense word or the string of nonsense words can be discarded from our language, but if we discard from our language "I feel Smith's toothache" that is quite different. The second seems nonsense, we are tempted to say, because of some truth about the nature of the things or the nature of the world ... The task will be to show that there is in fact no difference between these two cases of nonsense, though there is a psychological distinction in that we are inclined to say the one and be puzzled by it and not the other. We constantly hover between regarding it as sense and nonsense, and hence the trouble arises. [49]

There are not different kinds of nonsense, Wittgenstein wants to persuade us, but only nonsenses which are more psychologically attractive than others, more difficult to recognize as simply nonsense, more tempting to describe as substantively about something, even as "profound" [50].

Ironically, then, to take seriously Wittgenstein's notion that there can be no philosophical theses, and to take seriously the Tractatus, we need to take quite seriously Wittgenstein's own claim that, insofar as his own work embodies "propositions" or "theses", it also is quite literally nonsense. Famously, this is point is explicit at the close of TLP, if only one is ready to "understand" it: it, TLP, is not "meaningful nonsense", or nonsense "gesturing at some profound truth" [51]. It (TLP) is mostly, perhaps entirely, plain nonsense, albeit nonsense that may prove useful to us in a "dialogical" process of neceforth coming to be less tempted to utter nonsense [52].

On the austere Conant/Diamond understanding of TLP, and of the way that TLP leads into Wittgenstein's later work, the "ideas" that there could possibly be such a thing as expressing the form of our language, or our thought, or of their presuppositions, are nonsensical. They do not amount to anything. Nor do they "gesture" at anything. There's no such thing as creeping up indirectly on "profound truths" which cannot be expressed "directly". (Of course, these remarks must be understood also to be transitional [53], to "empty" themselves just insofar as they apparently embody "theses", or "elucidations".)

Let us return directly to our concern with Sass by means then of looking again at Witgenstein on "solipsism", this time at the early Wittgenstein:

What we cannot think, that we cannot think: we cannot therefore say what we cannot think. (TLP 5.61) 
This remark provides a key to the question, to what extent solipsism is a truth. In fact, what solipsism means, is quite correct, only it cannot be said, but it shows itself. That the world is my world, shows itself in the fact that the limits of the language (the language which I understand) mean the limits of $m y$ world. (TLP 5.62)

Drawing the consequences we must from our Diamondian arguments above: when we have truly understood the Tractatus, when we have read right to its end "with understanding", then TLP 5.62 [54] is not to be read as stating that there is a truth to solipsism, only unfortunately we can't state it, as all attempts to state it end in nonsense. Once the whole of TLP has been read and "understood", 5.62 becomes, retrospectively, "merely" what we are inclined to "believe" about "solipsism"-we are inclined to believe that it is something that retains ineffable truth, even if we (as it were) unfortunately happen to be unable to state it. In fact, though, there is no "it". "Solipsism" is merely a name for a certain set of logical temptations, temptations from which we can potentially be delivered, once we cease to think of "it" as retaining a truth at all behind its "front" of nonsense. One needs if anything only to be persuaded that "it" can be most properly viewed as plain nonsense-something with which nothing can (as yet) be done-once it is "understood" (!) aright.

In fact then, "I'm the only person to exist" only superficially resembles a real sentence of English, and fails to gesture at anything beyond itself (in this way, it is relevantly like "I feel Smith's toothache"). Whereas Sass's reading of solipsism would still have it gesture at the ineffable truth that it can appear to (want to) express. Sass's take on Wittgenstein strongly inclines toward the popular "ineffability" reading of TLP. But Conant and Diamond have shown, with their "resolute" reading of it, that we cannot hang anything on the idea of showing or "indirectly expressing" what can't be said [55].

My use of TLP on solipsism thus parallels Sass's use of the later philosophy of Wittgenstein on solipsism, except that I urge that we take more seriously than Sass that the results of the parallel are that what we are looking at - the schizophrenia of Schreber et al-makes no sense. The "structure" of Sass's version of schizophrenia, and the "logicality" Sass finds in Schreber, etc., must be understood by a serious Wittgensteinian as ultimately illustrative ... only of a ruleless and limitless incoherence.

In Paradoxes, Sass at times makes plain that he is interpreting something that is in central respects incoherent. But what is it to interpret something incoherent? Can an interpretation do anything other than give or render a certain coherence to something?

If certain forms of mental illness are usefully read, after Sass, as reflections of philosophical systems, etc. in the "mirror" of lived compulsions and realities, we must nevertheless not overemphasize how much we have succeeded in understanding the mental illnesses in question. There is an important sense in which, if Winch, Conant and Diamond are right on Wittgenstein, etc., as well as Sass being right on the salience of an analogy between Wittgenstein on solipsism on the one hand and Schreber et al. "on" solipsism on the other, then there can be no such thing as 
understanding schizophrenia. It just will not then be the kind of "thing" for which a hermeneutic can, strictly, be appropriate.

What we in fact have, after reading Sass, is, then - and this is very important-a much better chance of not hearing (say) Schreber's writings as simply an eruption of formless garbage, "word salad", or some such. They are that; but not only that, we might risk saying. They also have a certain "logic" to them-albeit a "logic", actually, only of what can be psychologically appealing. A psycho-logic, a pathologic. Roughly the same kind of "logic" that grips us when in the grips of a philosophical illusion. (As one is even in until one has truly "finished" reading TLP.) Insofar as Sass's project is on target, the language of schizophrenics will be understood to have much of the logic of the language of the solipsistic philosopher. But we must not lose sight of the crucial sense in which this is ... no logic at all. (Because it turns in on itself and ultimately and completely consumes itself.)

To recap: there are according to Diamond's cogent argument, her "austere" rendition of nonsense, no degrees of nonsense. There is simply nonsense: pseudosentences, forms of words, etc. for which we have not as yet found a use, and as of now literally cannot imagine so doing. "Solipsism" is not anything. And thus, if Sass is notionally right, then, ironically, there must be a real sense in which schizophrenia is not anything either. What is it like to be schizophrenic? It's quite literally not (literally) like anything. (But yet Sass still wants to tell us what it is like ...)

My answer to question (iii), then, is this: a sound understanding of Wittgenstein's philosophisizing raises serious doubts as to whether it could possibly be right for schizophrenia to turn out to make sense, even if we suspend my "Winchian" worries about Sass-i.e. even if schizophrenia is notionally "best interpreted" as a lived analogue of solipsism.

\section{Conclusions}

The two main lines of thought in the section above, lines of thought developed from Winch and Diamond respectively, are, I believe, thoroughly complementary [56]. Together, they result in the following provisional conclusions (conclusions which in this final section I will explore and develop a little further).

There cannot be a successful interpretation of serious schizophrenia, because there cannot be true self-understandings of people with schizophrenia [57] there to be the basis for such interpretations. Any interpretation will fail to present effectively the central aspects of the phenomenon, which are best regarded as nonsensical, as literally incomprehensible. For whereas almost all human actions can be described (or, in particular kinds of cases, interpreted) such as to yield understanding, we have seen particular reason, in the case of "Apollonian" mental illness, to suppose that much of the strange stuff that theorists in the "human sciences" have attempted to interpret can only be made sense of in an arbitrary or indefinitely variable way. Which is as much as to say that it cannot be made sense of [58]. You cannot use Wittgenstein to gain insights into nonsense-and problem cases of schizophrenia centrally involve the problematics of dealing with nonsense. There is no hermeneutic deciphering to be had of the alleged "essential rationality" of what is utterly 
non-rational or (what comes to the same thing here) "hyper-rational" [59]. (Such that even if solipsism is allowed to stand as productive analogy base for schizophrenia, Sass's argument still does not go through.)

Here is Wittgenstein: "I do not interpret [when] I feel at home in the present picture. When I interpret, I step from one level of thought to another" [60]. One interprets if one is not "at home" and has some decent hope of genuinely being able to get (at least closer to) "home" by means of interpreting (and no hope of being able to do so simply by, e.g. describing, or acting). If there is some distinction between better and worse interpretations, some criterion for establishing that one's interpretation has sent one happily "homeward bound" ... But what if these conditionals are not fulfilled? If there is no chance of getting home, nor any clear sense of being closer to farther from home? Then interpretation will be pointless and hopeless.

Though that something (e.g. much schizophrenic discourse) is in significant part uninterpretable, or nonsensical, must always, again, be adjudged only provisionally, nevertheless, that it $i$ is sometimes the wisest judgement to make ...

To sum up. In Section 2 of this paper, I used Wittgensteinian methods, including application of the work of Winch, Diamond and Conant, to challenge Louis Sass's "Wittgensteinian" interpretation of schizophrenia. I considered possible analogies which these philosophers offer which may help us understand the non-understandability of hard cases of schizophrenia. That is, having raised serious doubts (via Winch) as to whether, logically, "schizophrenic language" can pointfully and meaningfully be interpreted, I intimated an austere "reading" (via Diamond and Conant) of this "language" (i.e. of solipsism) as nonsense. If my approach is along roughly the right track, then Sassian hopes of interpreting schizophrenia via (diagnosed) philosophy are quite in vain. For those aspects of schizophrenia which have been found troublesome and which Sass has tried to interpret are, I have suggested, absolutely at best "comprehensible" along the lines of the nonsense of the Tractatus. We are presented by Wittgenstein with the illusion of alien or ineffable thoughts, and then if we are lucky we come to see clearly that this is an illusion-that they are no thoughts at all. That, it seems, is what we must say of "schizophrenic thoughts" too. (And this is a surprising conclusion to reach via a "humanistic" approach to the words and actions of Schreber et al., an approach which refuses, unlike some "scientistic" approaches, to treat these utterances more or less as sheer instances of "word salad"-or at least of rampant cognitive dysfunction-from the beginning.)

Mine remains, however, somewhat of a sympathetic critique of Sass; for it is not as if I think a better hermeneutic than his is available to take its place [61]. The reader will have to judge whether, in the light of my critique, Sass's "thought-experiment" has cast a sufficiently substantial degree of illumination to have been worth its hazards (or, indeed, whether mine has; for my paper too is at times "trafficking" in nonsense, engaging with your and my temptations to mire ourselves in nonsense) [62]. Or whether, rather, it is unfortunate that Sass has not followed resolutely enough the track laid out by the quotation from Wittgenstein which he (Sass) used as the epigraph to his book, The Paradoxes of Delusion: "You must always be puzzled by mental illness" ... [63].

It turns out, if the paragraph above can be trusted, that Jaspers was after all 
half-right on the language of mental illness. "Full-blown" schizophrenic discourse is not best regarded as interpretable - though for slightly different grounds from those that Jaspers gave. It is uninterpretable not exactly because it is "irrational", or "ill-formed", or "childish" or "foreign". Nor even because it is a mystery beyond the reach of ordinary human minds. Rather, schizophrenia is-in its more challenging and serious aspects- "something" that we have always implicitly known is incomprehensible ... because there is in the end no thing there for us to understand, not even a "world". (There is only a mass of contradictions, which is as much-and as little - as to say: nothing.)

This is why Wittgenstein said what he said of schizophrenia (see the epigraph to this paper). It does not matter whether we say that such a person does not love, cannot love, refuses to love, has no concept of love, loves in a totally different way, or whatever: there can be no such thing as getting schizophrenia right. You can call being able to say everything and nothing - being able to say whatever you like"understanding", if you wish! I would prefer to restrict the use of that term to contexts in which there is a reasonably clear distinction between understanding and not understanding someone. What we can be intelligibly said to understand in another, in the sense of understanding what their actions are, or understanding their motives for action, or "empathetically" understanding them, etc., is (most of) the hurly-burly and variety of ordinary life. But most serious schizophrenia does not fall under that heading. It is better seen, roughly, as the persistent semblance of another language-much like the semblance of another language that we find in Wittgenstein's "solipsist" or his "private linguist", a philosopher subject to an illusion of sense, an illusion that his words, in the way he finds himself wishing to employ them, mean anything at all.

Sass does not adequately consider the possibility that Schreber's words cannot properly be understood as a form of thinking. As it stands, that sentence is ambiguous. Most often, a Wittgensteinian will mean by a remark such as I have just made that someone's words can normally only be adequately understood in concert with what they are doing, not just as an index of what they are purportedly thinking to themselves. That is right, but my point in this paper has as it were pointed in the opposite direction, toward a line of thought that is more rarely required: that some people's words (namely, a severe schizophrenic's words) cannot in the end be understood as a form of thinking at all.

We can at most hope to "diagnostically" describe or re-create "schizophrenic language"; or, often better, just let it stand there:

Objects are stage trappings, ... geometric cubes without meaning. People turn weirdly about, they make gestures, movements without sense; they are phantoms whirling on an infinite plain, crushed by the pitiless electric light. And I-I am lost in it, isolated, cold, stripped, purposeless under the light... Madness was finding oneself permanently in an all-embracing Unreality. [64]

I would attempt no "translation". This is a paradigm for describing a certain lived experience, we might say. But that doesn't mean that sense can be made of it. 
That this is so is, I have allowed, not something which ought to be concluded too quickly, but only after extensive trying, just as we ought not to give up trying to understand a difficult passage in Heidegger or Derrida until we are absolutely exhausted. If we must conclude what I am urging we conclude, then that ought to give us a certain sense of regret and "loss"-but I have suggested that it is not a loss that is avoidable that can be reversed; it is important to see that in one important respect there is, if I am right, nothing that has actually been lost.

I have argued that we can use Wittgenstein to "approach" schizophrenia only in the quite attenuated sense illustrated in this Section 3 of this paper. And thus the most apposite genuinely Wittgensteinian conclusion to draw from the whole [65] might be the following: philosophy (at best), rather than trying to interpret or explain, leaves the language of serious mental illness as it is [66].

\section{Acknowledgements}

Thanks to audiences at Bolton Institute, Bolton (UK); at the Senior Seminar of the Centre for Ethics and Social Policy at Manchester University, Manchester; at the Cognitive Science Institute, University of Houston, Houston, TX; at the University of Illinois, Chicago, IL; at the Philosophy Society of the University of East Anglia, Norwich; at the NEH Summer Institute on Philosophy and Psychopathology, Cornell University, Ithaca, NY, on 10 July 1998; and at the "Author [L. Sass] Meets Critics" session at the Pacific APA, Berkeley, CA, on 28 March 1997-especially to my co-symposiasts there, Ian Hacking, Anne Jacobson, and (especially) Louis Sass. Thanks also to Cora Diamond, Kelly Dean Jolley, George Downing, Lisa Shapiro, Aaron Zimmermann, Jonathan Smith, Luke Mulhall, Wil Coleman, Jeff Coulter, Tobyn De Marco, Martin Batchelor, Michael Gorski, Alan Malachowski, Wes Sharrock, Dave Francis, Emma Willmer, Anne De Vivo, Cees van Leeuwen, two anonymous reviewers, (heartily) to Jim Conant and Jim Guetti, and (most heartily of all) to Ivan Leudar.

\section{Notes}

[1] Quotes taken from p. 87 of Sass (1994b).

[2] See Sass (1997), p. $203 \mathrm{f}$.

[3] See especially pp. 199-205 of Sass (1992) for his critique of Derrida, whom he sees as needing, like traditional philosophy, to be diagnosed by the (counter-)philosophy of Wittgenstein, Heidegger and Foucault.

[4] And supplementarily, of Heidegger and Foucault.

[5] Sass (1994).

[6] "The Apollonian illnesses", we might call these. For instance, on OCD as "Apollonian", compare Rapoport (1990), pp. 53-55, 118-122 and 200-201.

[7] See e.g. the Conclusion of his (forthcoming), and the Epilogue to Madness and Modernism (1992).

[8] This feature of schizophrenia is explored in greatest detail by Sass (2000).

[9] 1922 (henceforth TLP).

[10] If that isn't an oxymoron-a question implicitly addressed throughout Section 2, below.

[11] See p. 39f. of Paradoxes.

[12] A frustration often felt too by philosophers, and mystical writers ... 
[13] Schreber's name for those "inventions" of his imagination was: "fleeting-improvised-men".

[14] See Philosophical Investigations (Wittgenstein, 1958; henceforth PI), para. 119: "The results of philosophy are the uncovering of one or another piece of plain nonsense and of bumps that the understanding has got by running its head up against the limits of language. These bumps make us see the value of the discovery". Cf. Renée (1951), p. 136: "Only those who have lost reality and lived for years in the Land of cruel, inhuman Enlightenment can truly taste the joy in living and prize the transcendent significance of being a part of humanity".

[15] Sass, 1994, p. 23. (See also pp. 43-45; and Madness and Modernism, pp. 44f, 354.).

[16] Cf. p. 50 of Paul Gibbs (1997, pp. 47-52); and Read (1998), a paper on which I partly draw here. In case the reader is worried that I appear to be courting the identification of schizophrenia with philosophy, let me remark: that I am at most analogizing schizophrenia to traditional/metaphysical philosophy, and my "Reply to Gibbs" sets out clearly the manifest differences between a philosopher (almost any philosopher) and a sufferer from mental illness.

[17] There is also an implicit hint here that even realizing this may not actually help anyone in this condition. A therapeutic attempt to show the fly the way out of the fly-bottle will not help if the "fly" feels the attempt, not to mention the bottle and of course the world, the common life, outside it-and even themselves, as we shall see-to be unreal ... (cf. note 16 above).

[18] Saying this should again not lead us to neglect that schizophrenics spend a substantial proportion of their time in mundane procedures of "reality-testing"; any more than one should neglect the amount of time spent by, say, the Azande, or the "savages" discussed by Frazer, in irrigating their land, battling their enemies, etc. (see the discussion of Winch, etc., below).

[19] Given certain initial premises, Schreber quasi-scientifically constructs a system which leads logically into ... the most obscure and (literally) absurd contradictions. This is quite literally rationality running amuck, "science" out of control.

[20] Sass, 1994, p. 55. It is important to realize, in understanding Sass here, that "inner" and "outer", "private" and "public" are terms understood idiosyncratically by Schreber. At one stage of his illness Schreber progressively withdraws into his own body and finds more and more of his body external to himself, "outer", beyond his control. "So he can't be a solipsist-because much of his body, and even of his soul, his self, is external to his 'true' self (cf. Laing); whereas a solipsistic outlook would have the world be 'part of' the self?!" But Schreber is at this point on the road to becoming nothing - just the consequence which Sass predicts would eventuate from a quasi-solipsistic starting point ...

[21] A supplementary objection: 'Some of Schreber's 'solipsistic' moments seem, in his own account, to presuppose the existence of real public spaces in which they (e.g. the mosquito or butterfly 'miracles') occur, and thus are not really solipsistic". In response: firstly, again, the logic of solipsism leading directly to its negation(s), these may simply be "combining incompatible 'moments'" in the "dialectic" of solipsism; second, we must recall that the Memoirs were composed when Schreber had partially recovered, and was endeavouring to prove to the courts that he was "competent". His Memoirs are a composite of what he was experiencing at the time and his new-found re-interpretation of that experience.

[22] For confirmation of this account of Wittgenstein's achievement, see especially PI, paragraphs $402-403$.

[23] Chesterton (1959), p. 19. Cf. also Stanley Cavell, an important influence on Sass: "One of my favourite insights in Kant, one of the achievements that seems most astounding to me, is his actual systematizing of various forms of reason itself gone mad ... So that what Wittgenstein calls the bewitchment of the mind by language seems to me to join a central philosophical tradition of worrying about reason uncontrolled, turning into its opposite”. Conant (1989), pp. 57-58.

[24] The widespread conventional focus on the so-called "negative symptoms" of schizophrenia has arguably often been unhelpful — presupposing something like deficit, rather than deep difference. See Sass's (forthcoming).

[25] 1999; especially p. 34f.

[26] And, of course, understanding.

[27] We need to think here in the kind of ways suggested concretely by Garfinkelian Ethnomethodology, as explicated for instance by Mike Lynch (1993), pp. 14-17. Lynch's and Winch's ap- 
proaches are happier here than (say) Charles Taylor's, Weber's, or Jaspers's (1963/1923)—but Sass's approach is I think much closer to (say) Taylor's than to Winch's.

[28] Reprinted in Wilson (1970). One should note that Winch is by normal standards fairly "liberal" on the question of understanding - he is suggesting that much that seems irrational or incomprehensible is so only on a poor reading of it. In a sense, my whole question in this paper is: can Winch's "liberality" concerning understanding the "alien" effectively be used with regard to a particular set of cases, namely, certain philosophical illusions and (especially) psychopathological delusions?

[29] In Wilson (1970), p. 92.

[30] In Wilson (1970), p. 93; italics mine.

[31] Loosely paraphrasing a Wittgensteinian slogan, one might try simplifying my line here as follows: don't look for the interpretation, look for an adequate description.

[32] And need not necessarily interpret it. This is important: because interpretation will normally entail imposition.

[33] "Nearly always", meaning: except in certain narrowly intellectual contexts - such as much interpretation of poetry or of philosophy, wherein "interpretation" may indeed be just what is called for.

[34] Consider the example from Sass cited above. Ivan Leudar's account of Schreber et al. is here an important (Garfinkelian/Wittgensteinian) alternative to Sass's (see Sass, 2000).

[35] For basic references, see earlier notes. We are in this paragraph in part anticipating the more detailed rendition of Wittgenstein's account of solipsism that I give, after Diamond, in answer to question (iii), below.

[36] What we can unmisleadingly be said to understand is I think the panoply of (ordinary) human psychology, not severe mental illness-just as Wittgenstein says (1980, p. 77): "Suppose you say of the schizophrenic: he does not love, he cannot love, he refuses to love-what is the difference?!" When one can talk as one pleases, there is no question of one's attaining a correct interpretation, or even a better rather than a worse one. For detail, see Section 3, below; for now, one might put all this in a contemporary Anglo-American idiom as follows: while Quine's or Davidson's "indeterminacy" pictures are tenuous, problematic and exaggerated with regard to ordinary human interaction, they are true of much interaction with schizophrenics. On this last-important-point, I agree with Simon Evnine (1989).

[37] Should we regret the lack of such a community to sustain a schizophrenic's world-view? This ethical/practical question may be somewhat moot, because in serious cases we have good grounds for thinking that there could not be a community to sustain it. Thus we might risk saying that schizophrenics don't have a "form of life" (as suggested in note 39, below). I cannot then endorse W. Blankenburg's view (1971); for while (like Sass) he argues well that schizophrenia constitutes more a different than a deficient way of being-in-the-world, he does not adequately consider a third possibility: that "it" rather "constitutes" various ways of ... not being-in-the-world at all.

[38] For severe schizophrenia is in practice quite largely defined by the absence of same.

[39] We might then risk the following quasi-Wittgensteinian remark: "If a severe schizophrenic were to speak, we could not understand them". For while we can imagine the Zande "form of life", we can only imagine that we imagine Schreber's. For exposition of this particular employment of the word "imagine", see Diamond's powerful essay (2000). But a "form of life" which cannot really be imagined, which cannot be understood, is not interpretable; indeed, is surely not best termed a "form of life" at all.

[40] Construed, of course, in something more like a Lévy-Bruhlian than a Winchian way.

[41] One possible project then would be this: to find out where Schreber is self-consciously puzzled by his bizarre "world" and "dialogically" engage them ... Such points may be of crucial importance in testing critically whether any sense can be made of Schreber's "world". This is more or less Ivan Leudar's project in his fascinating Voices of Reason (2000).

[42] 1951, p. 56.

[43] 1951, pp. 55-56 (italics mine). Cf. also pp. 42, 121.

[44] For instance, Laing and his ilk successfully established, I think, that some schizophreniform talk 
and action which had previously been dismissed was in fact quite meaningful and reasonable, when looked at in the right socio-individual context. Cf. also pp. 80-81 of Giddens (1984). Giddens is another significant influence on Sass.

[45] Here I am presupposing a roughly Cavellian rather than (say) Rortian reading of Wittgenstein. That is, a (non-absolute) distinction, for certain "practical" philosophical purposes, between speaking "inside" and "outside" language-games. For detail, see Jim Conant (1991a), and the papers by Crary, Cavell, and Conant in Crary and Read (2000); and on the non-absoluteness of the distinction, see Scheman (1996).

[46] Or, similarly, "The world is my world", or "I know I'm in pain", or "I am here", etc.; unless one has actually found a genuine context for the use of the sentence in question (e.g. in the last case, if one of us has dropped the torch in a cave we're exploring together).

[47] "Throwing away the ladder" in Conent (1991b), pp. 197-198. See also Wittgenstein (1969), para. 35f. I am drawing here on some earlier material which can be found at greater length in Read (2000).

[48] Conant (1991b), pp. 197-199 (italics mine).

[49] From unpublished 1934 Lectures - see p. 106 of Diamond's (1991) (italics mine). Cf. also Conant's and E.Witherspoon's essays in Crary and Read (2000).

[50] This is not contradicted by (e.g.) PI 282. My point is not to make the dogmatic - nonsensical!assertion that there really is only one kind of nonsense, but to suggest that no category of "profound nonsense" or "nonsense in virtue of an incompatibility between the component-words the utterance" will, to use Diamond's words, ultimately be found satisfactory by one.

[51] Crucially, because, contrary to popular belief, there just is no role in TLP for the showing of anything by means of nonsense. "Showing", in Wittgenstein's sense, is effected at best only by non-nonsensical (i.e. senseful and some "senseless"-not nonsensical) propositions.

[52] That process is the import for Conant and Diamond of TLP 6.54. See Conant (1991b).

[53] And the opposition between "transitional" versus "solid/permanent" is in turn itself both founded originally in everyday use and ... transitional, not able to carry weight for long ...

[54] It is worth comparing to this quotation from the Tractatus the words of the gifted autist Donna Williams (1995), on the concepts of " $m y$ world" and "the world". What is key is her eventual fragile recognition (on p. 113), in the course of her gradual recovery, that "The distinction between 'my world' and 'the world' implied that I had a choice to be in 'the world' or not. The realization that autism stole this choice from me [through apparently barring access to 'the world'] became the linchpin for the final shattering truce that would bring my world-under-glass crumbling to the ground. I learned that there never was and never had been a 'my world' " (my emphasis).

[55] See notes 50 and 51, above. For Diamond's most telling account of what it is like to enter into illusions of sense - of what it is like, e.g. to imagine that we imagine something, when there is no such thing as literally imagining that (non-) "thing"- the reader is strongly advised to consult Diamond (2000), especially p. 67 and p. 73.

[56] This is hardly surprising - see, for example, Winch's very sympathetic response to Diamond's philosophy (1992).

[57] Again, let me stress that the model of "self-understanding" here is not necessarily anything to do with self-consciousness, with accurate reflection in consciousness. It is rather to do with what Ethnomethodologists call the mundane accountability, reflexivity and indexicality of human actions (normally)—see again Lynch (1993).

[58] When you can say almost whatever you like, then there are not criteria for sensicality. So you might as well not say anything.

[59] Sass does not take seriously enough that Schreber's "excessive" rationality is a drastic failure of rationality.

[60] 1967, para. 234.

[61] I have questioned, rather, whether any interpretation here can itself issue in anything other than misleading nonsense.

[62] If Conant and Diamond are right, this is of course inevitable: Wittgenstein's own work is no more 
than a ladder (and not a ladder to anywhere). This again draws some of the sting of my critique of Sass, for it is less of a criticism of him that he ends up doing something nonsensical, attempting something radically unattemptable (i.e. the interpretation of serious schizophrenia), if there is no alternative hereabouts to the purveyance of nonsense. The only question is how self-conscious Sass is about his nonsense, and how useful and perspicuous his paper is as a ladder to be thrown away. For, once again, my paper too is a "ladder". Its rungs include the fantasy that one can make sense of schizophrenia; and the fantasy that one can make sense of my own remarks about that fantasy ...

[63] p. ix (emphasis mine); the quotation is taken from Rhees (1984).

[64] This is Renée, writing retrospectively; quoted on p. 47 of Sass's Madness and Modernism.

[65] That is, having noted that we can somewhat deflate categories such as "schizophrenic" by means of thinking of this and related concepts as "family resemblance" concepts, and that "scientific psychological" categories are arguably in important respects moral taxonomic categories (see the work on this particularly of Jeff Coulter), and having looked in more detail than philosophers typically do at the language-games or illusions of language-games in play here, in and around "schizophrenia".

[66] Cf. PI, para. 124.

\section{References}

Blankenburg, W. (1971). Der Verlust der Naturlichen Selbstvertaendichkeit. Stuttgart: Ferdinand Enke V. Chesterton, G.K. (1959). Orthodoxy. New York: Doubleday.

Conant, J. (1989). An interview with Stanley Cavell. Bucknell Review, 32, 1.

Conant, J. (1991a). The search for logically alien thought. Philosophical Topics, 20, 115-180.

Conant, J. (1991b). Throwing away the top of the ladder. The Yale Review, 79, 328-364.

Crary, A. \& ReAD, R. (Eds) (2000). The New Wittgenstein. London: Routledge.

DiAmond, C. (1991). The Realistic Spirit. Cambridge, MA: MIT.

DiAmond, C. (2000). Ethics, imagination and the method of the Tractatus. In A. CRARY \& R. READ (Eds) The New Wittgenstein. London: Routledge.

Evnine, S. (1989). Understanding Madness? Ratio, 2, 1-18.

GIBBS, P. (1997). Schizophrenia as philosophy: a grounding for philosophical counselling. Contemporary

Philosophy, XIX, 47-52.

Giddens, A. (1984). The Constitution of Society. Cambridge: Polity.

Jaspers, K. (1963/1923). General Psychopathology. Manchester: Manchester University Press.

Leudar, I. (2000). Voices of Reason, Voices of Insanity: Studies of Verbal Hallucinations. London: Routledge.

Lyas, C. (1999). Peter Winch. Teddington: Acumen.

Lynch, M. (1993). Scientific Practice and Ordinary Action. Cambridge: Cambridge University Press. RApoport, J. (1990). The Boy Who Couldn't Stop Washing. London: HarperCollins.

READ, R. (1998). There is no good reason to think that philosophical counselling can cure schizophrenia: a reply to Gibbs. Contemporary Philosophy, XX, 59-62.

READ, R. (2000). In closing: the New Hume's new antagonists: on the relevance of Goodman and Wittgenstein to the New Hume debate. In R. READ \& K. Richman (Eds) The New Hume Debate. London: Routledge.

RENÉE. (1951). Autobiography of a Schizophrenic Girl. New York: Meridian.

RHEES, R. (Ed.) (1984). Recollections of Wittgenstein. Oxford: Oxford University Press.

SASs, L. (1992). Madness and Modernism. New York: HarperCollins.

SASs, L. (1994a). The Paradoxes of Delusion. New York: Cornell.

SASs, L. (1994b). Civilized madness: schizophrenia, self-consciousness and the modern mind. History of the human sciences, 7, 83-120.

SASS, L. (1997). The consciousness machine: self and subjectivity in schizophrenia and modern culture. In NeISser \& Jopling (Eds) The Conceptual Self in Context. Cambridge: Cambridge University Press. 
SASs, L. (2000). "Furtive abductions": schizophrenia, the lived body, and dispossession of self. Arobase: Fournal des Lettres et Sciences Humaines, 4; available online at: <http://www.liane.net/arobase/ $>$. SASS, L. (forthcoming). Schizophrenia, disembedding and the modern age.

Scheman, N. (1996). Forms of life: mapping the rough ground. In SLUGA \& STERn (Eds) Cambridge Companion to Wittgenstein. Cambridge: Cambridge University Press.

Williams, D. (1995). Somebody Somewhere. London: Doubleday.

Wilson, F. (Ed.) (1970). Rationality. Oxford: Blackwell.

WINCH, P. (1970). Understanding a primitive society. In F. WILsON (Ed.) Rationality. Oxford: Blackwell.

WINch, P. (1992). Persuasion. MidWest Studies in Philosophy, XVII, 123-137.

Wittgenstein, L. (1922/1933). Tractatus Logico-Philosophicus. London: Routledge.

Wittgenstein, L. (1958/1953). Philosophical Investigations. London: Macmillan.

Wittgenstein, L. (1967). Zettel. Berkeley, CA: University of California Press.

Wittgenstein, L. (1969). On Certainty. New York: Blackwell.

Wittgenstein, L. (1980). Culture and Value. Oxford: Blackwell. 